\title{
A PROSPECTIVE RANDOMISED CONTROL STUDY TO ASSESS THE EFFICACY OF INTRAOPERATIVE DEXMED INFUSION ON EMERGENCE AGITATION AND QUALITY OF RECOVERY IN NASAL SURGERY
}

\author{
R. Manimaran 1 , K. Aravind ${ }^{2}$
}

${ }^{1}$ Assistant Professor, Department of Anaesthesiology, Tagore Medical College and Hospital.

2Junior Resident, Department of Anaesthesiology, Tagore Medical College and Hospital.

\section{ABSTRACT}

\section{BACKGROUND}

Emergence agitation is usually common after nasal surgery. We underwent investigation to find the effects of intraoperative dexmedetomidine infusion on emergence agitation and quality of recovery after nasal surgery in adult patients.

\section{MATERIALS AND METHODS}

One hundred patients undergoing nasal surgery were randomized into two groups. The dexmedetomidine group (Group $D, n=50$ ) received dexmedetomidine infusion at a rate of $0.4 \mathrm{mcg} / \mathrm{kg} / \mathrm{hr}$ from induction of anaesthesia until extubation, while the control group (Group C, $\mathrm{n}=50$ ) received volume-matched normal saline infusion as placebo. Propofol $1.5-2 \mathrm{mg} \mathrm{kg} / \mathrm{kg}$ and fentanyl 1 $\mathrm{mcg} / \mathrm{kg}$ were used for induction of anaesthesia, and sevoflurane was used for maintenance of anaesthesia. The incidence of agitation, haemodynamic parameters, and recovery characteristics were evaluated during emergence. A 40-item quality-ofrecovery questionnaire (QoR-40) was provided to patients $24 \mathrm{~h}$ after surgery.

\section{RESULTS}

The incidence of agitation was lower in Group D than Group C (28 vs 52\%, $\mathrm{P}=0.041)$. Mean arterial pressure and heart rate were more stable in Group D than in Group C during emergence $(\mathrm{P}<0.05)$. Time to extubation and respiratory rate at extubation were similar between the groups. Global QoR-40 score at 24 hrs. after surgery was higher in Group D (median [range], 183 [146 -198]) compared with Group C (178 [133-196]) (P=0.041).

\section{CONCLUSION}

Intraoperative infusion of dexmedetomidine provided smooth and haemodynamically stable emergence. It also improved quality of recovery after nasal surgery.

\section{KEYWORDS}

Nasal Surgery, Dexmedetomidine, Infusion, Emergence Agitation.

HOW TO CITE THIS ARTICLE: Manimaran R, Aravind K. A prospective randomised control study to assess the efficacy of intraoperative dexmed infusion on emergence agitation and quality of recovery in nasal surgery. J. Evolution Med. Dent. Sci. 2018;7(08):969-974, DOI: $10.14260 /$ jemds/2018/222

\section{BACKGROUND}

Emergence agitation is a post anaesthetic phenomenon that develops in early phase of recovery from general anaesthesia. Studies reported that ear, nose and throat surgeries have higher incidence of emergence agitation in adults 1,2 (incidence of 21.3\%). Emergence agitation from general anaesthesia may lead to serious complications such as hypoxia, aspiration pneumonia, bleeding or re-operation. Nasal surgery is associated with a higher incidence of emergence agitation due to sense of suffocation ${ }^{1,2}$.

Dexmedetomidine is a selective Alpha 2 adrenergic agonist ${ }^{3,4}$. It suppresses the activity in the descending noradrenergic pathway, which modulates nociceptive neurotransmission, terminates propagation of pain signals leading to analgesia. The hypnotic effects are mediated by the hyperpolarisation of noradrenergic neuron, which suppresses neuronal firing in the locus coeruleus along with inhibition of norepinephrine release ${ }^{5}$. This suppression of

'Financial or Other Competing Interest': None.

Submission 08-12-2017, Peer Review 03-02-2018,

Acceptance 12-02-2018, Published 19-02-2018.

Corresponding Author:

R. Manimaran,

4E, Pearl Block, Bashyam Navarathna,

Thiruneermalai Main Road,

Chrompet, Chennai-600044.

E-mail:mani.maran@me.com

DOI: $10.14260 /$ jemds $/ 2018 / 222$ inhibitory control triggers neurotransmitters that decrease histamine secretion, producing hypnosis similar to sleep, without ventilator depression, making dexmedetomidine a near ideal sedative ${ }^{6,7,8}$.

However, dexmedetomidine can cause haemodynamic changes including hypotension, hypertension and bradycardia9,10. Because hypertension is common after loading dose of dexmedetomidine we have administered a continuous infusion of 0.4 micro gm $/ \mathrm{kg} / \mathrm{hr}$ without loading dose in our study.

\section{MATERIALS AND METHODS}

100 people who underwent intranasal surgery in the period of Dec-2016 to Dec-2017 in Tagore Medical college were randomly separated into two groups group $\mathrm{C}$ and group $\mathrm{D}$ with each 50. Inj. Dexmedetomidine at a rate of $0.4 \mathrm{mcg}$ $/ \mathrm{kg} / \mathrm{hr}$ was started in patients who was randomized to group $\mathrm{D}$ and volume matched normal saline (loaded in $50 \mathrm{ml}$ syringe) was started in group $\mathrm{C}$ patients. Post-extubation agitation was recorded and compared.

The study was conducted on 100 patients aged between 18 to 58 years undergoing elective nasal surgeries at Tagore medical college during the academic year from December 2016 to Dec 2017. Patient details were collected from MRD section in Tagore Medical College. Case and controls were matched by sex, age group and type of surgeries. 


\section{Method of Collection of Data}

100 patients, belonging to ASA grade I or II, aged between 18 to 58 years, undergoing elective nasal surgeries were included in this study. Data was collected through patient interviews using questionnaires and surgical records. Enrolled patients were interviewed. Interviews were conducted in local language. Initial pilot testing of the questionnaire was already done.

The study population will be randomly divided into 2 groups with 50 patients each-

- $\quad$ Study group D- received dexmedetomidine infusion at a rate of $(0.4 \mathrm{mcg} / \mathrm{kg} / \mathrm{hr})$ from induction until 5 minutes after extubation. (Dexmedetomidine diluted in normal saline at a concentration of $4 \mathrm{mcg} / \mathrm{ml}$ in $50 \mathrm{ml}$ )

- $\quad$ Study group C- received volume matched normal saline infusion (loaded in $50 \mathrm{ml}$ syringe).

\section{Inclusion Criteria}

- Age group of 18-58 years of both sex.

- $\quad$ ASA grade I or II.

- Requiring general endotracheal anaesthesia.

- Patients aged >15 years who gave consent to be the part of study.

\section{Exclusion Criteria}

Known allergies to midazolam, dexmedetomidine, clonidine, benzodiazepines and/or red dye.

\section{No Parent or Legal Guardian Present to give Informed Consent}

Patients with a body mass index of 30 or higher, with congestive heart failure, a bradycardia rate under 50 per minute, first degree or more atrioventricular block, uncontrolled high blood pressure, clotting disorders, allergic fungal sinusitis or infection with multiple nasal polyps, renal or liver dysfunction and those who did not understand the meaning of the study or could not read the agreement, were excluded from the study.

\section{Limitations of the Study}

Due to short duration of study, convenience sampling technique was followed. Thus, sampling size was also calculated by convenience. The results of the study cannot be generalised due to the potential bias resulting from the sampling technique and sample size estimation.

All the patients underwent pre-anaesthetic evaluation on the day before the surgery. The entire procedure was explained to the patient. Informed written consent was taken. An hour prior to surgery, vitals such as (BP, $\mathrm{HR}, \mathrm{SPO}_{2}$ ) was recorded. The anaesthetist who was not involved in the study loaded drugs as per sealed envelope technique. Patient was shifted inside OR. Monitors such as ECG, NIBP, Oxygen saturation probe were connected and baseline vitals such as heart rate (HR), blood pressure (SBP, DBP) and oxygen saturation were monitored.

Drugs and equipment necessary for resuscitation and general anaesthesia were kept ready.

Patients were pre-oxygenated with 6 litres of oxygen through bag and mask via closed circuit. The patient received IV midazolam $(0.04 \mathrm{mg} / \mathrm{kg}) 5$ minutes prior to induction.

11,12 Prior to induction Inj. glycopyrrolate $0.2 \mathrm{mg}$ was given. After 5 minutes of monitoring, Inj. dexmedetomidine at a rate of $0.4 \mathrm{mcg} / \mathrm{kg} / \mathrm{hr}$ was started in patients who was randomized to group D and volume matched normal saline (loaded in $50 \mathrm{ml}$ syringe) was started in group C patients.

Infusion was started before the induction of anaesthesia. ${ }^{13} \mathrm{General}$ anaesthesia was induced by the use of fentanyl 1 $\mathrm{mcg} / \mathrm{kg}$ and propofol $1.5-2 \mathrm{mg} / \mathrm{kg}$, inj. vecuronium $0.1 \mathrm{mg} / \mathrm{kg}$ was used to facilitate endotracheal intubation. Air entry was checked by 5 -point auscultation. The tube was fixed and then connected to ventilator. Anaesthesia was maintained by $\mathrm{N}_{2} \mathrm{O}: \mathrm{O}_{2}$ (2:1) and sevoflurane which was titrated to 1 MAC (minimal alveolar concentration) ${ }^{5,6}$

${ }^{14}$ Mechanical ventilation was maintained with $8 \mathrm{ml} / \mathrm{kg}$ tidal volume and ventilation frequency was adjusted to maintain $\mathrm{ETCO}_{2}$ between $30-40 \mathrm{mmHg}$.

Bradycardia was treated with Inj. Atropine $(0.6 \mathrm{mg})$, tachycardia was treated with Inj. Metoprolol (2-5 mg incremental doses) and hypotension (defined as MAP $<30 \%$ of baseline on two consecutive readings within 2-3 minutes) not responding to fluid bolus is treated with ephedrine at 6 mg increments) ${ }^{15,14}$.At the time of nasal packing, IV Ketanov was given to both groups.

Once the surgery is complete, oral suctioning was performed and reversal agents ${ }^{13}$ (Glycopyrrolate $0.01 \mathrm{mg} / \mathrm{kg}$ and neostigmine $0.05 \mathrm{mg} / \mathrm{kg}$ ) was given after confirming the return of neuromuscular function. Inhalational agent was cut off in both the groups and mechanical ventilation was converted to manual ventilation at $8 \mathrm{~L} / \mathrm{min}$. The patient was not disturbed, except by continual verbal requests to open their eyes. All other stimuli were prevented. Extubation was performed when patient began to breathe spontaneously and be able to respond to verbal requests. dexmedetomidine or saline was stopped after 5 minutes of extubation. 16Emergence is defined as the time interval from stoppage of inhaled anaesthetics to 2 minutes after extubation.

During emergence the level of agitation was evaluated using the Ricker sedation- agitation scale and each patient's maximum agitation were noted.

\section{Ricker Sedation Agitation Scale}

1. Minimal or no response to noxious stimuli.

2. Arousal to physical stimuli but does not communicate.

3. Difficult to arouse but awakens to verbal stimuli or gentle shaking.

4. Calm and follows commands.

5. Anxious or physically agitated and calm to verbal instructions.

6. Requiring restraint and frequent verbal reminding of limits.

7. Pulling of tracheal tube, trying to remove catheters or striking at staff.

The length of period from stoppage of inhaled anaesthetics to first verbal response and extubation were noted.

Haemodynamic parameters were recorded for 2-5 minutes after the infusion is begun, at 5 minutes intervals for 3 minutes and at 15 minutes interval until 1 hour.

\section{RESULTS}

\section{Statistical Analysis}

Sample size was calculated using "G*Power3" free software. Using $\alpha=0.05$ with a power of $90 \%$, the total sample size was 
calculated at 108. After assuming a $10 \%$ drop out rate, 50 patients were allocated to each group.

Statistical analyses were performed using SPSS 12.0 (SPSS, Inc., Chicago, IL, USA). The normality of distribution was assessed with the Kolmogorov-Smirnov test. Values are expressed as the number of patients (\%). Parametric data (weight, recovery time, maximum RSAS score, and VAS) were analysed with independent t-test. Non-parametric data (age, height, duration of surgery, duration of recovery room stay) were analysed using the Mann-Whitney test. Categorical variables (gender, ASA class, type of surgery, and incidences of EA and PONV) were analysed by the Fisher's exact test. A $P<0.0125$ was considered statistically significant, accounting for a Bonferroni correction in comparison of four groups and a $\mathrm{P}<0.05$ was considered statistically significant in comparison of experimental groups and control groups. 5,17The change in the end-tidal concentration of sevoflurane, propofol and fentanyl were analysed by repeated measures ANOVA, and post-hoc testing was performed using the turkey and t-test. A $\mathrm{P}<0.05$ was considered statistically significant between two groups.

A total of 108 patients were assessed for eligibility and 100 subjects were enrolled in the study. After randomization, the participants either received dexmedetomidine or saline during nasal surgery. All patients completed the study (Fig. 1). Patient characteristics and operative procedures were similar between the two groups (Table 1).

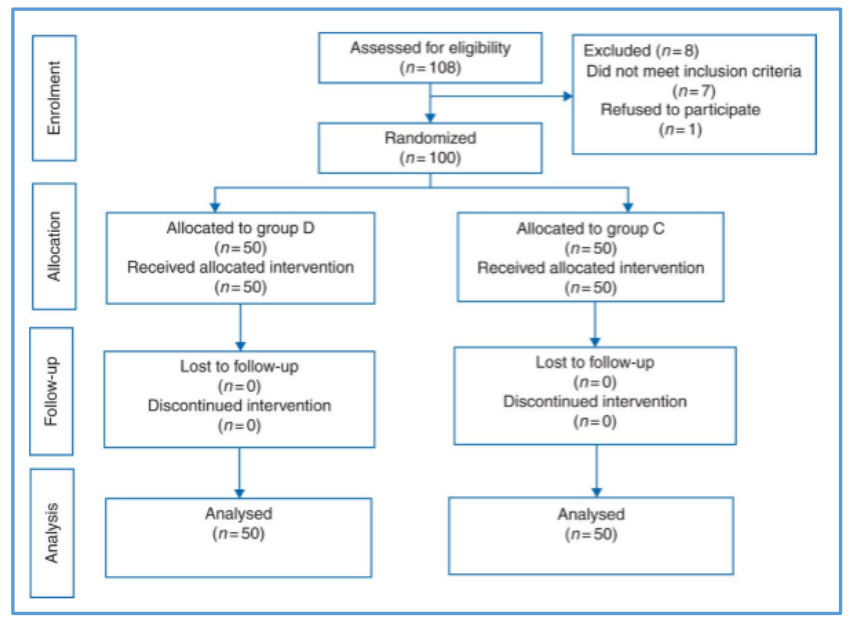

Figure 1

Patient assignment to study group (randomized) and treatment protocols. D, dexmedetomidine; C, control with normal saline.

\begin{tabular}{|c|c|c|c|}
\hline & $\begin{array}{c}\text { Group D } \\
(\mathbf{n = 5 0 )}\end{array}$ & $\begin{array}{c}\text { Group C } \\
\text { (n=50) }\end{array}$ & P-value \\
\hline Age (yr) & $33(18-58)$ & $32(18-58)$ & 0.863 \\
\hline Gender (M/F) & $38(12)$ & $32(18)$ & 0.656 \\
\hline Height (cm) & $169(10)$ & $169(8)$ & 0.956 \\
\hline Weight (kg) & $66(12)$ & $66(11)$ & 0.894 \\
\hline Hypertension & $1(2 \%)$ & $1(2 \%)$ & 1.000 \\
\hline Type of surgery & & & 0.952 \\
\hline Septoplasty & $26(52 \%)$ & $23(46 \%)$ & \\
\hline Ethmoidectomy, both & $5(10 \%)$ & $6(12 \%)$ & \\
\hline $\begin{array}{c}\text { Septoplasty and } \\
\text { ethmoidectomy }\end{array}$ & $16(32 \%)$ & $17(34 \%)$ & \\
\hline
\end{tabular}

\begin{tabular}{|c|c|c|c|}
\hline Septorhinoplasty & $3(6 \%)$ & $4(8 \%)$ & \\
\hline Duration of surgery (min) & $51(25)$ & $57(29)$ & 0.282 \\
\hline $\begin{array}{c}\text { Infusion duration of study } \\
\text { drug (min) }\end{array}$ & $77(29)$ & $73(27)$ & 0.534 \\
\hline $\begin{array}{c}\text { Amount of intraoperative } \\
\text { fluid (ml) }\end{array}$ & $506(216)$ & $524(227)$ & 0.689 \\
\hline
\end{tabular}

Table 1. Patient characteristics and operation details. Values are mean (SD), median (range) or number (\%). D, dexmedetomidine; $C$, control with normal saline; study drug means dexmedetomidine or normal saline

The incidence of emergence agitation was lower in Group D than in Group C ( $28 \%$ vs $52 \%, \mathrm{P}=0.041)$, while dangerous agitation was not different between the groups (Fig. 2). Agitation subsided within $5 \mathrm{~min}$ after extubation in all patients $8,18,11$.

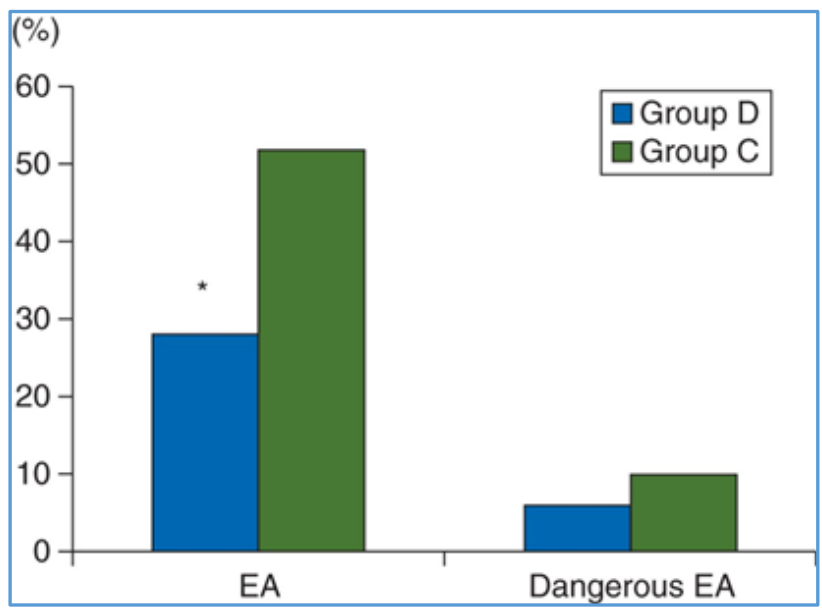

Figure 2

Incidence of emergence agitation and dangerous emergence agitation. D, dexmedetomidine; C, control with normal saline; EA, emergence agitation. Emergence is defined as the period from the end of surgery to $2 \mathrm{~min}$ after extubation. ${ }^{18}$ Agitation is defined as a sedation-agitation scale score of $\geq 5$. Dangerous agitation is defined as a sedationagitation scale score $=7$. ${ }^{*} \mathrm{P}=0.041$ compared with Group C.

Age-adjusted MAC of desflurane was not different between the groups during the surgery $(0.9 \pm 0.2$ in both groups at $10 \mathrm{~min}$ after the start of surgery and $0.9 \pm 0.2$ in Group D vs $1.0 \pm 0.2$ in Group C at $30 \mathrm{~min}$ after the start of surgery). At the completion of surgery, it was $0.9 \pm 0.2$ in Group D and $0.9 \pm 0.1$ in Group C. Other parameters related to emergence from general anaesthesia and recovery in the PACU are provided in Table 2. The time from desflurane discontinuation to extubation (8.7 $\mathrm{min}$ in Group D vs $7.8 \mathrm{~min}$ in Group C, $\mathrm{P}=0.092$ ) was not different, even though the time to verbal response was longer in Group D compared with Group C (8.1 min vs $7.0 \mathrm{~min}, \mathrm{P}=0.044)$. There were no differences between the groups in respiratory rate or BIS at the time of extubation, nor were there differences in coughing during emergence. Pain scores and administration of analgesics and antiemetics in the PACU were not different between the groups. Length of PACU stay was similar in both groups even though two patients in Group D had residual sedation (sedation-agitation scale score $=3$ ) upon arrival in the PACU16. There were no complications, including 
desaturation or laryngospasm, during emergence or while in the PACU.

\begin{tabular}{|c|c|c|c|}
\hline & $\begin{array}{c}\text { Group D } \\
(\mathbf{n = 5 0 )}\end{array}$ & $\begin{array}{c}\text { Group C } \\
\text { (n=50) }\end{array}$ & P-value \\
\hline $\begin{array}{c}\text { Time to verbal } \\
\text { response (min) }\end{array}$ & $8.1(2.9)$ & $7.0(2.5)$ & 0.044 \\
\hline $\begin{array}{c}\text { Time to extubation } \\
\text { (min) }\end{array}$ & $8.7(2.9)$ & $7.8(2.6)$ & 0.092 \\
\hline $\begin{array}{c}\text { Respiratory rate at } \\
\text { extubation (/min) }\end{array}$ & $17.0(4.5)$ & $17.5(4.4)$ & 0.633 \\
\hline BIS at extubation & $81.5(5.7)$ & $83.2(5.6)$ & 0.145 \\
\hline $\begin{array}{c}\text { Grade of cough } \\
\text { during emergence }\end{array}$ & $2(0-3)$ & $2(0-3)$ & 0.469 \\
\hline $\begin{array}{c}\text { Residual sedation in } \\
\text { PACU }\end{array}$ & $2(4 \%)$ & 0 & 0.495 \\
\hline NRS for pain in PACU & $2(0-6)$ & $2(0-8)$ & 0.061 \\
\hline Analgesics in PACU & $4(8 \%)$ & $8(16 \%)$ & 0.218 \\
\hline Antiemetics in PACU & $3(6 \%)$ & $9(18 \%)$ & 0.065 \\
\hline $\begin{array}{c}\text { Length of PACU stay } \\
\text { (min) }\end{array}$ & $16.2(5.3)$ & $16.4(5.5)$ & 0.897 \\
\hline
\end{tabular}

Table 2. Recovery characteristics. Values are mean (SD), median (range) or number (per cent). $D$,

dexmedetomidine; $C$, control with normal saline; $B I S$, bispectral index; NRS, numerical rating scale; PACU, postanaesthetic care unit. Time to verbal response or extubation is defined as the time period from desflurane discontinuation to verbal response or extubation. Residual sedation is defined as sedation-agitation scale score $\leq 3$ at arrival in PACU11. Grade of cough: 0 , no cough; 1 , single cough; 2 , cough persistence $<5 s ; 3$, persistent cough for $\geq 5$ $s$ or bucking. Emergence is defined as the period from end of surgery to 2 min after extubation

MAP and HR during operation and emergence are shown in Figure 3. Intraoperative MAP and HR were similar in both groups. However, Group D demonstrated more stable haemodynamic changes during the emergence period compared with Group C (Bonferroni corrected P<0.05). 17,13,15 During the operation, ephedrine was administered to seven patients in Group D and four patients in Group C ( $\mathrm{P}=0.338)$, while esmolol was administered to six patients in Group $\mathrm{C}$ and no patients in Group D $(\mathrm{P}=0.027)$. No patient in either group experienced bradycardia.

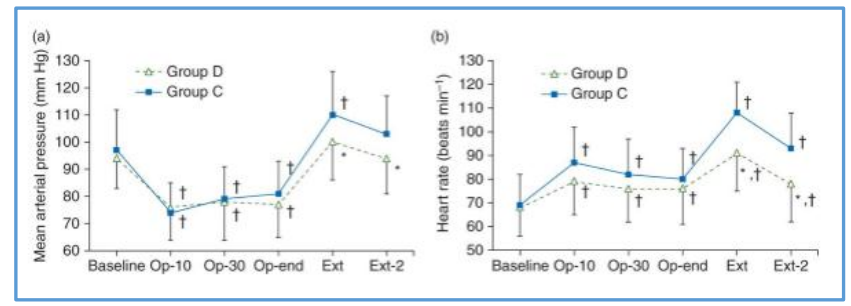

Figure 3

Haemodynamic changes that occurs during operation and emergence. (a) MAP, and (b) HR. Baseline, before anaesthetic induction; 0p-10, 10 min after the start of operation; Op-30, $30 \mathrm{~min}$ after the start of operation; Op-end, end of operation; Ext, extubation; Ext-2, 2 min after extubation. Data are expressed as mean (SD). $\mathrm{P}<0.05$ compared with Group C. $\mathrm{P}<0.05$ compared with baseline in each group.

The QoR-40 score at $24 \mathrm{hrs}$ after surgery is demonstrated in Table 3. The median global score in Group D was 183 (range: 146-198). This was significantly higher than the QoR40 score of 178 (range: 133-196) for Group C ( $\mathrm{P}=0.041)$. Group D demonstrated the higher scores in pain dimension when compared to Group C $(\mathrm{P}=0.030)$.

\begin{tabular}{|c|c|c|c|}
\hline & $\begin{array}{c}\text { Group D } \\
\text { (n=50) }\end{array}$ & $\begin{array}{c}\text { Group C } \\
(\mathbf{n}=50)\end{array}$ & P-value \\
\hline \multicolumn{4}{|c|}{ QoR-40 dimensions } \\
\hline Emotional state & $40(33-45)$ & $40(25-45)$ & 0.107 \\
\hline Physical comfort & $53(39-60)$ & $52(38-58)$ & 0.358 \\
\hline $\begin{array}{c}\text { Psychological } \\
\text { support }\end{array}$ & $35(28-35)$ & $35(23-35)$ & 0.073 \\
\hline $\begin{array}{c}\text { Physical } \\
\text { independence }\end{array}$ & $24(14-25)$ & $24(10-25)$ & 0.094 \\
\hline Pain & $32(22-35)$ & $30(17-35)$ & 0.030 \\
\hline Global QoR-40 & $183(146-198)$ & $\begin{array}{c}178(133- \\
196)\end{array}$ & 0.041 \\
\hline $\begin{array}{c}\text { Table 3. QoR-40 dimensions and global scores. Values are } \\
\text { median (range). D, dexmedetomidine; C, control with } \\
\text { normal saline }\end{array}$ \\
\hline
\end{tabular}

\section{DISCUSSION}

The results of this prospective double-blind randomized study suggest that the intraoperative continuous dexmedetomidine infusion $(0.4 \mathrm{mcg} / \mathrm{kg} / \mathrm{h})$ until extubation was effective in reducing the incidence of emergence agitation after nasal surgery without delay of extubation or increasing incidence of other complications $1,2,3$. In addition, intraoperative use of dexmedetomidine produced more stable haemodynamic changes during extubation and enhanced patient-reported global quality of recovery at 24 hrs after surgery ${ }^{10}$.

Emergence agitation has been reported in upto 20\% of adult patients after general surgery. Male gender, type of surgery, inhalation anaesthetics, presence of tracheal tube and preoperative benzodiazepine medication are risk factors for postoperative agitation in adults. Emergence agitation is especially common after ENT surgery, where $55.4 \%$ of patients experienced agitation ${ }^{11}$. High incidence of emergence agitation after ENT surgery may be attributable to a sense of suffocation. In our study, we only included patients who were expected to have a higher risk of emergence agitation for the following reasons: the patient required eachside nasal packing, a tracheal tube was used, benzodiazepine premedication and inhalation anaesthetics were administered. As expected, in Group $C$, the incidence of emergence agitation was $52 \%$, which is similar to a previously reported result.

Dexmedetomidine induces sedation and analgesia without respiratory depression. Therefore, it has been used for preventing emergence agitation. Intraoperative administration of dexmedetomidine reduced emergence agitation in children by $57-70 \%$ compared with control groups. Consistent with previous results, dexmedetomidine was also effective in reducing emergence agitation by $46 \%$ in adults.

Even though time to verbal response was significantly longer in Group D than Group C, time to extubation was not significantly different between the two groups. This may be because of higher incidence of agitation in Group C. Extubation is sometimes delayed during agitation because of security of airway patency. In our study, the longest time to extubation was $18 \mathrm{~min}$, in a subject who received 
dexmedetomidine infusion for 114 min. Meanwhile, maximum duration of dexmedetomidine infusion was 156 min, and extubation was performed 10 min after desflurane was discontinued. ${ }^{19}$ As dexmedetomidine does not depress respiratory drive inspite of its sedative property, maintenance of dexmedetomidine infusion until extubation may be safe, considering the results that the mean BIS value at extubation was 81 and mean respiratory rate was $17 / \mathrm{min}$ in Group D. However, the sedative effect of dexmedetomidine may not be enough to prevent cough after nasal surgery using desflurane anaesthesia. Use of desflurane for maintenance of anaesthesia was reported to result in faster emergence, but higher incidence of coughing compared with sevoflurane.

Dexmedetomidine can cause haemodynamic changes including hypotension (30\%), hypertension (12\%), and bradycardia (9\%).Because hypertension is common after administration of the loading dose of dexmedetomidine 10,20 , we administered a continuous infusion of $0.4 \mathrm{mcg} /$ $\mathrm{kg} / \mathrm{h}$ without a loading dose, which was also effective in reducing agitation during weaning from mechanical ventilation in critically ill patients. Intraoperative MAP and HR tended to be lower in Group D compared with Group C, however, there were no significant differences between the groups. Then, incidence of hypotension that required ephedrine treatment was not different between the groups and none of the patients in Group D had bradycardia10,20. Risk of bradycardia with dexmedetomidine may be offset by a dose-dependent increase in HR with desflurane.

Maintenance of dexmedetomidine until extubation provided more stable haemodynamic changes during emergence in our study. However, in a previous study, in which dexmedetomidine infusion of $0.2 \mathrm{mcg} / \mathrm{kg} / \mathrm{h}$ was maintained during extubation, MAP and HR were not different between the dexmedetomidine and control groups. These different results may be attributed to the different age groups of the patients (adults vs children), or differing infusion concentration $(0.4 \mathrm{mcg} / \mathrm{kg} / \mathrm{h}$ vs $0.2 \mathrm{mcg} /$ $\mathrm{kg} / \mathrm{h})$.

Global QoR-40 scores were significantly higher in Group D compared with Group C. Among the five dimensions in the QoR-40, pain was the most significantly improved among Group D patients. The QoR-40 is a useful objective measurement of quality of recovery after anaesthesia and surgery, and it is the only assessment tool that fulfils all of the eight quality-of-recovery criteria-appropriateness, reliability, validity, responsiveness, precision, interpretability, acceptability, and precision.

There are several limitations to this study. First, we cannot rule out the possible effects of pain and preoperative anxiety on emergence agitation. However, severity of pain might be similar between the groups during emergence because NRS for pain and use of additional analgesics in the PACU was not different between the groups. Additionally, preoperative anxiety has been reported to have no relationship with postoperative agitation. Secondly, we did not conduct a preoperative QoR-40 questionnaire. However, preoperative values might be similar in both groups because we included in both groups patients who were 18-58 years old, were classified into ASA class I-II, and did not have cognitive impairment or a history of chronic use of antipsychotic medications. Thirdly, it is uncertain whether the beneficial effects of dexmedetomidine persisted beyond 1 day after nasal surgery because QoR-40 scores were only collected at $24 \mathrm{hrs}$. after surgery. Fourthly, as sample size calculation was based on the incidence of emergence agitation, sample size may not be enough to check quality of recovery. Therefore, the significantly higher Global QoR-40 scores observed in Group D may be underpowered.

In conclusion, maintenance of intraoperative dexmedetomidine infusion $(0.4 \mathrm{mcg} / \mathrm{kg} / \mathrm{h})$ until extubation provided smooth and haemodynamically stable emergence without complications after nasal surgery. It also improved the quality of recovery 1 day after surgery.

\section{CONCLUSION}

To conclude, maintenance of low dose infusion of dexmedetomidine $(0.4 \mathrm{mcg} / \mathrm{kg} / \mathrm{hr})$ without bolus dose during nasal surgeries provides smooth and hemodynamically stable emergence and improved quality of recovery following extubation.

\section{REFERENCES}

[1] Kim SY, Kim JM, Lee JH, et al. Efficacy of intraoperative dexmedetomidine infusion on emergence agitation and quality of recovery after nasal surgery. British Journal of Anaesthesia 2013;111(2):222-8.

[2] Khurshid H, Muneer K, Malla MS. Effect of Dexmedetomidine on Emergence Agitation after Nasal Surgeries. Indian Journal of Clinical Anaesthesia 2015;2(3):126-30.

[3] Patel A, Davidson M, Tran MC, et al. Dexmedetomidine infusion for analgesia and prevention of emergence agitation in children with obstructive sleep apnea syndrome undergoing tonsillectomy and adenoidectomy. Anesthesia \& Analgesia 2010;111(4):1004-10.

[4] Khan ZP, Ferguson CN, Jones RM. Alpha-2 and imidazoline receptor agonists. Their pharmacology and therapeutic role. Anaesthesia 1999;54(2):146-65.

[5] Shukry M, Clyde MC, Kalarickal PL, et al. Does dexmedetomidine prevent emergence delirium in children after sevoflurane-based general anesthesia? Pediatric Anesthesia 2005;15(12):1098-104.

[6] Guler G, Akin A, Tosun Z, et al. Single-dose dexmedetomidine reduces agitation and provides smooth extubation after pediatric adenotonsillectomy. Pediatric Anesthesia 2005;15(9):762-6.

[7] Erdil F, Demirbilek S, Begec Z, et al. The effects of dexmedetomidine and fentanyl on emergence characteristics after adenoidectomy in children. Anaesthesia and Intensive Care 2009;37(4):571-6.

[8] Kim DJ, Kim SH, So KY, et al. Effects of dexmedetomidine on smooth emergence from anaesthesia in elderly patients undergoing orthopaedic surgery. BMC Anesthesiology 2015;15(1):139.

[9] Schulz KF, Altman DG, Moher D, et al. CONSORT 2010 statement: updated guidelines for reporting parallel group randomised trials. BMC Medicine 2010;8(1):18.

[10] Wajima Z, Yoshikawa T, Ogura A, et al. The effects of intravenous lignocaine on haemodynamics and 
seizure duration during electroconvulsive therapy. Anaesthesia and Intensive Care 2002;30(6):742-6.

[11] Kim HJ, Kim DK, Kim HY, et al. Risk factors of emergence agitation in adults undergoing general anesthesia for nasal surgery. Clinical and Experimental Otorhinolaryngology 2015;8(1):46-51.

[12] Lepouse C, Lautner CA, Liu L, et al. Emergence delirium in adults in the post-anaesthesia care unit. British Journal of Anaesthesia 2006;96(6):747-53.

[13] Scheinin B, Lindgren L, Randell $\mathrm{T}$, et al. Dexmedetomidine attenuates sympathoadrenal responses to tracheal intubation and reduces the need for thiopentone and peroperative fentanyl. British Journal of Anaesthesia 1992;68(2):126-31.

[14] Hall JE, Uhrich TD, Barney JA, et al. Sedative, amnestic and analgesic properties of small-dose dexmedetomidine infusions. Anesthesia \& Analgesia 2000;90(3):699-705.

[15] Gerlach AT, Murphy CV, Dasta JF. An updated focused review of dexmedetomidine in adults. Annals of Pharmacotherapy 2009;43(12):2064-74.
[16] Martin E, Ramsay G, Mantz J, et al. The role of the $\alpha 2$ adrenoceptor agonist dexmedetomidine in postsurgical sedation in the intensive care unit. Journal of Intensive Care Medicine 2003;18(1):29-41.

[17] Kim HS, Byon HJ, Kim JE, et al. Appropriate dose of dexmedetomidine for the prevention of emergence agitation after desflurane anesthesia for tonsillectomy or adenoidectomy in children: up and down sequential allocation. BMC Anesthesiology 2015;15:79.

[18] Ohtani N, Kida K, Shoji K, et al. Recovery profiles from dexmedetomidine as a general anesthetic adjuvant in patients undergoing lower abdominal surgery. Anesthesia \& Analgesia 2008;107(6):1871-4.

[19] Grant SA, Breslin DS, MacLeod DB, et al. Dexmedetomidine infusion for sedation during fiberoptic intubation: a report of three cases. Journal of Clinical Anesthesia 2004;16(2):124-6.

[20] Mason KP, Zgleszewski SE, Dearden JL, et al. Dexmedetomidine for pediatric sedation for computed tomography imaging studies. Anesth Analg 2006;103(1):57-62. 